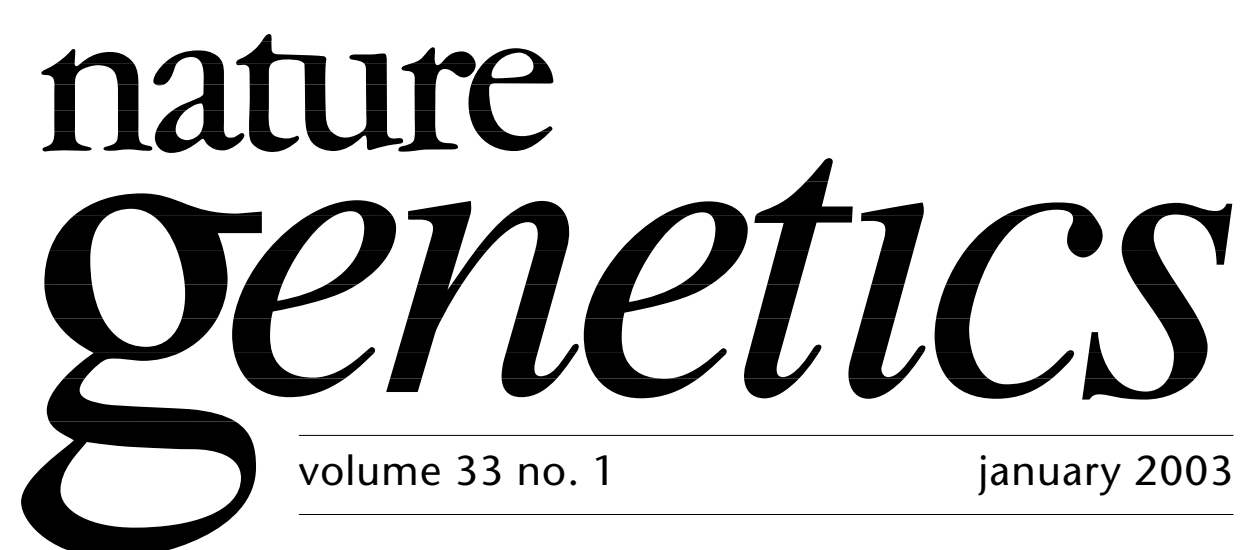

\title{
What's taking so long?
}

"It has been over six weeks since we submitted our manuscript..." "I was wondering if you had any news about our manuscript..." "I am appalled by the amount of time it has taken..." Sound familiar? It will be of little surprise to most that the review process at academic journals, including Nature Genetics, can sometimes take months. Why is that? The truth of the matter is that usually you need look no further than your own colleagues.

We all recognize that the peer review system is imperfect but necessary to ensure that only quality, reputable science is widely disseminated in research journals. It is a simple system of checks and balances that, thankfully, results in high-quality science being published in our pages. There is a burdensome fact that complicates the system, however-it is completely reliant on scientists donating their precious time to evaluate the work of others. Reviewers are well aware that their input can improve the quality of work being published in their field, keep them apprised of significant advances and, depending on how they view it, prevent bad science from getting out there or make sure that good science is rewarded with publication. Many scientists see their participation in the peer review process as an exercise in good citizenship; others see it as a burden, albeit a necessary one (still others see it as both). Either way, this is the system that is in place, and it is probably here to stay, despite many suggested changes to the system over the years.

There is one aspect of the process that we feel needs serious attention and perhaps discussion in the community. That is, many scientists, having assumed the responsibility of properly reviewing submitted manuscripts, are not holding up their end of the bargain. They may not send in their review within the agreed-on time frame, or they may send in a review that does nothing more than state a general opinion of the work without justifying that opinion, whether positive or negative. This is not to say that we as editors are always blameless or are incapable of making a poor decision on a manuscript. In our experience, however, manuscripts are usually delayed because of a single reviewer.

We are probably preaching to the choir when we say that it is essential that reviews be received in a timely manner so the authors of the manuscript can either modify their manuscript or take it to another journal should it be deemed by the reviewers' comments and editorial judgment to be inappropriate for our pages. What hangs in the balance is not just publication of a single paper for a lab. Labs are made up of people who rely on their publication record for grants, graduation and job prospects. When a potential reviewer is overstretched in his or her commitments, review of a manuscript is probably the first commitment set aside. 
Though it is inconvenient for editors, this tardiness is unlikely to affect publication of Nature Genetics. It is actually the author-perhaps at a key stage in his or her career-who will be most affected by significant delay. Grants can be denied, graduation delayed, job opportunities squandered, all as a result of delays in the process, and we need not discuss the ' $s$ ' word in detail (scooped). Although it might seem melodramatic to put it in such severe terms, it is a reality that many authors face. We as editors would prefer not to act as police, reminding referees of their obligations; unfortunately, time that could be devoted to assessing manuscripts is frequently pirated by this activity.

By committing to referee a paper, you are not only advising the editors on whether to accept or reject, you are providing authors with useful suggestions to improve their research. It is an integral part of the process that, when unfulfilled, further undermines the system of checks and balances. Often, referees will provide a very general impression of the work presented in a manuscript without justifying their view. This is sometimes seen in the reviews of well-established scientists who are either overburdened or feel that the flaws of a manuscript are self-evident. Indeed, we do take the general view of reviewers into account when making decisions, but more important to the editors and the authors is the reason for this view and suggestions for ways that the authors can address concerns raised.

So, what are we as editors to do about referees who don't hold up their end of the deal? We do keep track of the frequent offenders, and we do keep notes and statistics on reviewers. We do not, however, keep a 'black list' of the frequently tardy. The problem is actually much deeper than just weeding out the delinquent few. Most of the time, the referee in question has a reasonable track record. There needs to be a cultural change in the community whereby scientists do not agree to review a paper unless they can do so well. Extenuating circumstances will crop up, but it is your obligation to inform us that you cannot provide a review on time so that we can make other arrangements for review of the manuscript. Keep in mind that saying no to a request to review a paper will never damage your reputation in the eyes of the editors; not completing the task once accepted, however, may cause us to think twice about asking again.

We appreciate the great effort that goes into reviewing a paper. Moreover, we are frequently impressed by the care and thoughtfulness that the best referees lavish on a paper. That said, we urge you not to take on this responsibility if time and other pressing obligations will not permit you to do it well. Professional courtesy demands nothing less.

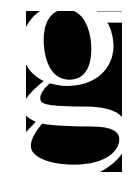

